\title{
Fiber effects in nutrition and gut health in pigs
}

\author{
Jan Erik Lindberg
}

\begin{abstract}
Dietary fiber is associated with impaired nutrient utilization and reduced net energy values. However, fiber has to be included in the diet to maintain normal physiological functions in the digestive tract. Moreover, the negative impact of dietary fiber will be determined by the fiber properties and may differ considerably between fiber sources. Various techniques can be applied to enhance nutritional value and utilization of available feed resources. In addition, the extent of fiber utilization is affected by the age of the pig and the pig breed. The use of potential prebiotic effects of dietary fiber is an attractive way to stimulate gut health and thereby minimize the use of anti-microbial growth promoters. Inclusion of soluble non-starch polysaccharides (NSP) in the diet can stimulate the growth of commensal gut microbes. Inclusion of NSP from chicory results in changes in gut micro-environment and gut morphology of pigs, while growth performance remains unaffected and digestibility was only marginally reduced. The fermentation products and $\mathrm{pH}$ in digesta responded to diet type and were correlated with shifts in the microbiota. Interestingly, fiber intake will have an impact on the expression of intestinal epithelial heat-shock proteins in the pig. Heat-shock proteins have an important physiological role in the gut and carry out crucial housekeeping functions in order to maintain the mucosal barrier integrity. Thus, there are increasing evidence showing that fiber can have prebiotic effects in pigs due to interactions with the gut micro-environment and the gut associated immune system.
\end{abstract}

Keywords: Breed, Gut health, Fiber, Pigs, Prebiotics, Utilization

\section{Introduction}

On a worldwide basis corn and soybean meal are the main staples in the diet for pigs and poultry, providing most of the energy and nutrients needed. It is argued that although other cereals, such as wheat, and byproducts, such as rice bran and distiller's grains, are used as alternative feedstuffs in part of the world the quantities available are not sufficient to replace corn and soybean meal in the global pig and poultry industry [1]. This may be correct and may apply to the industrialized livestock production, but may not be applicable to countries where a major part of the livestock production relies on smallholder farmers.

With more focus on small-scale family farming, in order to improve food security and minimize the negative impact on the environment and the climate, there are opportunities for more diversified composition of the diet with respect to feedstuffs included. Potential feed resources used for animals in many countries in

Correspondence: jan.erik.lindberg@slu.se

Department of Animal Nutrition and Management, Swedish University of Agricultural Sciences, P.O. Box 7024, Uppsala SE-75007, Sweden
Asia derive primarily from the vegetable foods and agroindustry co-products, such as cassava leaves, sweet potato vines, water spinach, rice bran, cassava residue, brewer's grain and tofu residue. They represent underutilized feedstuffs, most having high fiber content, which may impose limitations in their use in diets for monogastric animals, in particular young animals, due to their bulky nature and a limited capacity to ferment fiber [2]. Thus, in order to better utilize available fiber-rich feedstuffs in the diet, their chemical and physical characteristics has to be described and taken into account in feed formulation.

Dietary fiber has an important role in pig and poultry diets and a minimum level of dietary fiber has to be included to maintain normal physiological function in the digestive tract [3]. A major concern when including fiber in diets for mono-gastric animals is that high dietary fiber content is associated with decreased nutrient utilization and low net energy values [4]. However, the negative impact of dietary fiber on nutrient utilization and net energy value will be determined by the fiber properties and may differ considerably between fiber 
sources. Moreover, dietary fiber may have other positive effects such as to stimulate gut health, increase the satiety, affect behavior and overall improve animal wellbeing $[2,3,5,6]$. Despite the obvious need for dietary fiber in the diet it is not included in the nutrient requirement tables [7].

For a long time antibiotics have been used as growth promoters on a regularized basis to control the problems with commonly occurring enteric diseases, such as postweaning diarrhea and swine dysentery [6]. However, this is not a sustainable production system and the regular use of antibiotics in animal feed will promote bacterial resistance that may result in less efficient antibiotic treatments for human and animal diseases $[8,9]$. In addition, misusing antibiotics as feed additives for animal production can result in high antibiotic residues in animal products. Since 2006 antimicrobial growth promoters (AMGP) have been banned within EU and the goal is minimal use of antibiotics in food production. A similar development can be expected to take place also in other parts of the world.

In order to minimize the use of AMGP in animal production it is important to find ways to obtain a good animal health with other means. One possible way is changing diet composition and to use various dietary interventions. A huge amount of research has been performed in the area that aims to change the gut microbial composition, such as supplementation of probiotics, prebiotics, organic acids and dietary fiber [6]. It is believed that these types of dietary interventions have the potential to improve gut health.

\section{Dietary fiber}

The carbohydrate fraction can be divided according to glycosidic linkages into sugars, oligosaccharides and two broad classes of polysaccharides, starch and non-starch polysaccharides. Non-starch polysaccharides (NSP) together with lignin, has been defined as the dietary fibre (DF) fraction in feedstuffs and food, and can be used as a collective measure of their fibre content [10-12]. However, as non-digestible oligosaccharides and resistant starch have similar physiological effects in the body as NSP and lignin, although not being part of the cell wall structure, the definition should be extended to include these constituents [13].

The amount and composition of dietary fibre vary widely between and within feedstuff $[12,14,15]$. As a result, the dietary fibre content and its properties in a typical diet for any animal varies between production systems and countries due to availability of feed resources. A change in chemical composition of the plant material and their co-products not only depends on the botanical origin of the plants and the type of processing applied, but also on the tissue type and the maturity of the plant at harvesting time. The proportion of middle lamella, and primary and secondary cell wall in the plant material, together with the properties of the amorphous matrix connecting the cell walls, will determine both utilization and properties. The amorphous matrix usually shows considerable variation from tissue to tissue within plant and between plants. In monocotyledonous plants, such as cereals, the main cell wall NSP are arabinoxylans, cellulose and $\beta$-glucan [12]. In contrast, the amorphous matrix in dicotyledonous plants can differ markedly from that in monocotyledonous plants due to different tissue types, exemplified by the huge difference in content and properties of pectic substances $[16,17]$.

The physicochemical properties of dietary fibre are dependent on the polysaccharides that make up the cell wall and their intermolecular association which determine their solubility [17]. The major physicochemical properties that have been considered in animal nutrition are cation exchange capacity, hydration properties, viscosity and organic compound adsorptive properties. Characteristic for insoluble dietary fiber is that they increase rate of passage and faecal bulk whereas soluble dietary fiber increases the viscosity and hydration properties [18]. Hydration properties of the feed is very important for effective digestion to occur in the animal and can be characterized by the swelling capacity, solubility, water holding capacity (WHC) and water binding capacity (WBC). Recent studies showed a strong correlation between content of soluble non-cellulosic polysaccharides (S-NCP) and WHC in plant material and agroindustry co-products collected in Vietnam [15]. This could be due to the occurrence of more gaps within the cell matrix that can retain excess water in feed ingredients which are high in S-NCP. Similarly, it has been shown that the S-NCP fraction in co-products from vegetable food and agro-industries was linearly related to selected hydration properties, such as swelling and WBC [14] (Figure 1).

\section{Nutritional effects}

\section{Improving feed value}

Various techniques, such as pelleting, reduction of particle size and supplementation with exogenous enzymes can be applied to enhance nutritional value and utilization of available feed resources [19-21]. This may be most relevant for locally available feed resources to overcome the shortcomings of poor nutritive value $[6,22]$ due to high fibre content and of other components in the feed affecting the physicochemical properties.

The positive effects of enzyme addition is due to disruption of intact cell walls and release of entrapped nutrients or due to the changes in the physical properties of non-starch polysaccharides, such as viscosity and 


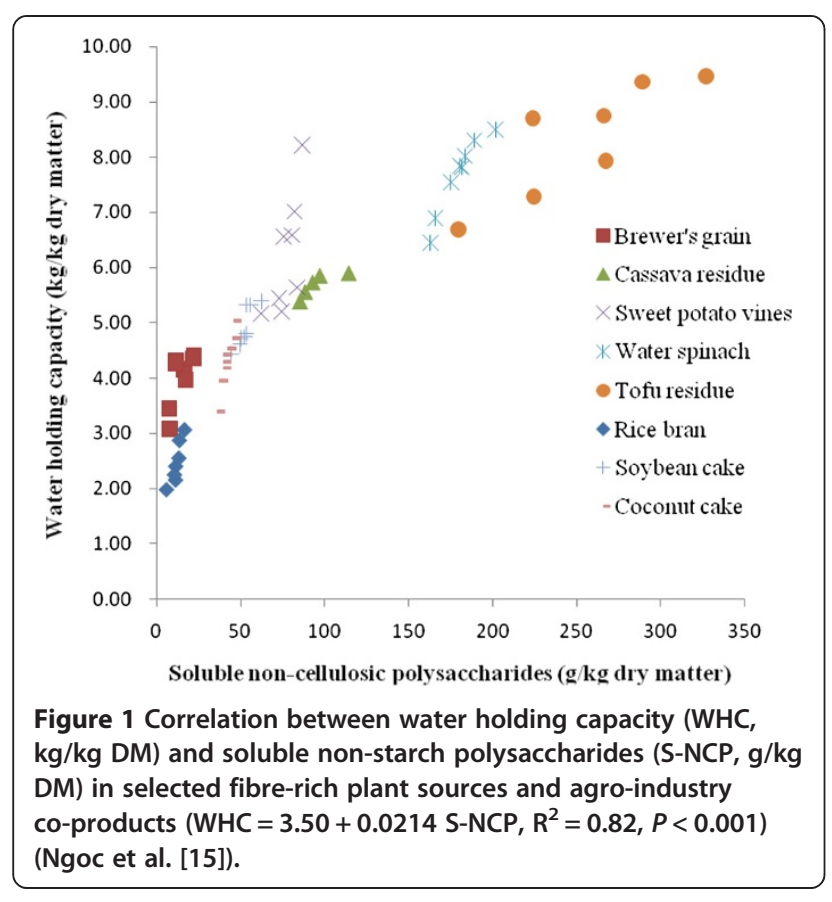

WHC, and/or changes in the composition and content of bacteria in the small and large intestine [23-25].

Reducing particle size has been reported to improve the feed efficiency and nutrient digestion of weaned pigs $[19,21]$. There appears to be a particle size by age of pig interaction in digestibility, resulting in a larger response in young as compared to older pigs [19]. This can be explained by the development of the digestive and absorptive capacity in the small intestine and increased colonization of carbohydrate-degrading microbiota in the large intestine with increasing age. There are also indications of a particle size by enzyme interaction for the total tract apparent digestibility of dietary components in pigs [21].

Reduction in particle size ( 1 versus $3 \mathrm{~mm}$ ) increased the total tract apparent digestibility of dietary components and the average daily gain (ADG) of Landrace $x$ Yorkshire pigs in the post-weaning period, but not in the growing period [26]. Moreover, addition of a multienzyme mixture (mixture of $\alpha$-amylase, $\beta$-glucanase, cellulase and protease) improved the total tract apparent digestibility of dietary components and growth performance in the post-weaning period [26]. However, there was an interaction between particle size and multienzyme supplementation on the total tract apparent digestibility of crude protein $(\mathrm{CP})$ and neutral detergent fibre (NDF) in the post-weaning period, such that multienzyme supplementation increased the total tract apparent digestibility of $\mathrm{CP}$ and NDF in the larger particle size diet ( $80 \%$ vs. $75 \%$, and $58 \%$ vs. $51 \%$, respectively), while there was no changes in a small particle size diet ( $80 \%$ vs. $78 \%$, and $59 \%$ vs. $55 \%$, respectively). However, in the growing period multi-enzyme supplementation had no positive effect on the performance and the total tract apparent digestibility of dietary components, with the exception of CP and NDF (Table 1).

\section{Fiber utilization}

Impact of age

Adult pigs have a more developed and larger GI tract, a lower feed intake per kg body weight, a slower digesta transit time and a higher cellulolytic activity than young pigs. This resulted in greater capacity of sows to digest fibrous components compared to young pigs [27] and it was shown that sows digest a larger part of the NSP in the small intestine than growing pigs [28]. They also showed that sows have a higher capacity to digest insoluble NSP, whereas the difference in digestibility of soluble NSP between growing pigs and sows were only marginal. It was suggested that because of the increased capacity to digest fibrous feedstuff by increased age and body weight, at least two different energy values, one for growing-finishing pigs and one for sows should be used for most feed ingredients in pig diets [4]. This has been implemented in the INRA net energy system for pigs (www.evapig.com).

In weaned pigs, age affected the total tract apparent digestibility of all dietary components except for NDF, with higher values at five than at three weeks postweaning [29].

\section{Impact of pig breed}

Digestive capacity and potential body protein deposition are two important traits associated with pig performance. However, in commercial pig breeding research has

Table 1 Impact of fiber source, particle size and enzyme treatment on dry matter intake (DMI), average daily gain (ADG) and feed conversion ratio (FCR) in post-weaned and growing pigs ${ }^{1}$

\begin{tabular}{|c|c|c|c|c|c|c|}
\hline \multirow{2}{*}{ Items } & \multicolumn{3}{|c|}{ Post-weaned pigs } & \multicolumn{3}{|c|}{ Growing pigs } \\
\hline & DMI & ADG & FCR & DMI & ADG & FCR \\
\hline \multicolumn{7}{|l|}{ Fiber source } \\
\hline Cassava root meal & 559 & $422^{\mathrm{a}}$ & $1.33^{\mathrm{a}}$ & 1289 & $597^{\mathrm{a}}$ & $2.16^{\mathrm{a}}$ \\
\hline Sweet potato vines & 550 & $385^{b}$ & $1.44^{\mathrm{b}}$ & 1271 & $540^{b}$ & $2.36^{\mathrm{b}}$ \\
\hline \multicolumn{7}{|l|}{ Particle size } \\
\hline Small (1 mm) & 556 & $416^{\mathrm{a}}$ & 1.34 & 1273 & 572 & 2.24 \\
\hline Large (3 mm) & 553 & $391^{b}$ & 1.42 & 1286 & 565 & 2.29 \\
\hline \multicolumn{7}{|l|}{ Enzyme addition" ${ }^{\#}$} \\
\hline- & 554 & $387^{b}$ & $1.44^{\mathrm{b}}$ & 1265 & 557 & 2.28 \\
\hline+ & 555 & $420^{\mathrm{a}}$ & $1.33^{\mathrm{a}}$ & 1295 & 580 & 2.24 \\
\hline SEM & 28 & 12 & 0.07 & 41 & 17 & 0.08 \\
\hline
\end{tabular}

'Data from Ngoc et al. [26]. Different letters within column indicates significant differences between treatments. SEM = standard error of the mean.

${ }^{\#}$ Multi-enzyme mixture ( $\alpha$-amylase, $\beta$-glucanase, cellulase and protease). 
mainly focused on factors associated with body lipid and protein deposition [30,31], while less attention has been directed to breed differences in the digestive capacity [32]. Thus, body protein and lipid mass and their deposition rates are key variables used in growth models to predict compositional changes in carcass muscle and fat tissue mass over time [30,33]. This priority can be explained by the increasing demand of consumers for meat quality in general and for lean meat in particular. It is also reflected in an increasing use of exotic breeds such as the Landrace, Yorkshire, Duroc and Hampshire for cross-breeding of native pigs, mainly in urban and periurban areas, in several countries in Asia. Crossbred Large White $\times$ Yorkshire (LY) pigs show higher growth rate and better feed conversion than native Mong Cai (MC) pigs, when fed the same daily amount of DM and CP $[34,35]$. This is due to greater potential for lean tissue accretion in LY than in MC pigs, as reflected in higher nitrogen retention [34,35].

However, indigenous breeds, such as the MC breed, may have better characteristics with regards to reproduction and are adapted to the local climate. Therefore, in Vietnam pure-bred MC sows are still commonly mated with boars of an exotic breed, usually Yorkshire or Landrace, using artificial insemination, and the off-springs are fattened in small-scale semi-intensive or intensive systems. Moreover, it has been shown that indigenous pig breeds may have a higher capacity to digest fibre than exotic pig breeds genetically improved to support high growth performance [22,34-36]. The main explanation to the improved digestibility in indigenous pigs is a longer MRT of digesta [37]. This will contribute to a more efficient digestion due to longer contact between digesta, digestive enzymes and absorptive surfaces [32], and between digesta and the gut microbiota [38]. A longer MRT in the indigenous MC pig can be explained by a larger GIT (in terms of diameter), reflected in more gut content, as compared to LY pigs. In accordance, it was reported that differences in gut content could explain the longer MRT in Iberian pigs than in Landrace pigs [39]. Earlier studies on indigenous and exotic pig breeds support the contention of greater length of the GIT in the indigenous pigs [36,40] (Figure 2).

In addition, recent studies show that there are interactions between breed and diet on LAB count and in the concentration of propionic acid in the ileum. Increased fibre level in the diet in combination with high soluble fiber content had a greater impact on the LAB count and the concentration of propionic acid in the ileum of MC pigs than of LY pigs [41]. This suggests differences in the gut microbiota activity and/or composition between MC and LY pigs.

Interestingly, there was also a breed effect on the small intestinal morphology in the ileum, while there were no breed related differences in the duodenum and jejunum.

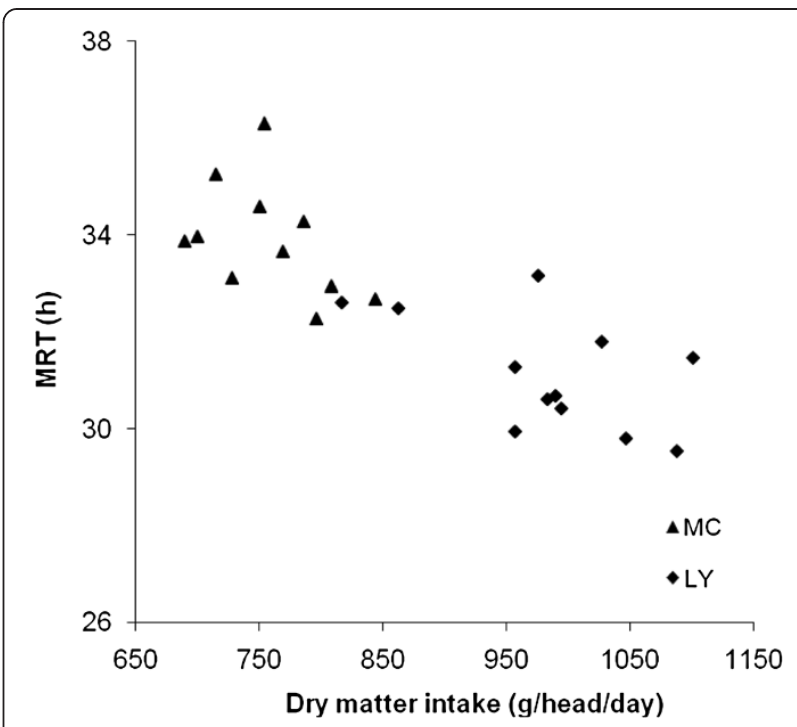

Figure 2 Impact of dry matter intake ( $g / h e a d /$ day) on mean retention time (MRT; $h$ ) of digesta in growing Mong Cai (MC) and Landrace $x$ Yorkshire (LY) pigs (Ngoc et al. [37]).

Mong Cai pigs had shorter villi, smaller villus width and greater crypt density in the ileum than LY pigs [41]. These differences in gut morphology can be explained by differences in digesta transit time and gut microbial activity [42]. A major part of the digested nutrients are absorbed in the proximal small intestine. This together with a rapid digesta passage and low microbial activity, results in less exposure to digesta components compared with the situation in the more distal small intestine. The MC pigs had a longer total tract mean retention time of solids than the LY pigs [37] allowing for longer contact between digestion products and absorptive surfaces [32].

Based on existing data, it appears reasonable to assume that different breeds can have different digestive capacity and will as a result show different response to the same diets in terms of nutrient utilization and performance.

\section{Effects on gut health}

\section{Gut microenvironment}

The maintenance of gut health is complex and relies on a delicate balance between the diet, the commensal microflora and the mucosa, including the digestive epithelium and the mucus overlying the epithelium [43]. The diet has a great impact on gut health, and it can provide either beneficial or harmful input $[2,6,44]$. The diet should be composed to create a balance between the gut, the microbiota and the gut environment and prevent disturbances in the gut. Dietary fibre interacts both with the mucosa and the microbiota and consequently has an important role in the control of gut health $[2,6,43]$. 
The complex microbial community in the gastrointestinal (GI) tract consists of different groups of microbes including bacteria, archaea, ciliate and flagellate protozoa, anaerobic phycomycete fungi and bacteriophages. Bacteria are the most abundant and studied microbes in this community. They are provided with substrates from the diet as well as components deriving from the host such as mucopolysaccharides, mucins, epithelial cells and enzymes [45]. With the introduction of molecular techniques to indentify the microbiota it has become apparent that only a minority of the GI microbes have been isolated by culture based methods [46] and consequently the knowledge we have today most likely needs to be revised in the future (Figure 3).

\section{Prebiotic effects}

The concept of prebiotics was initially defined as "non-digestible food ingredient that beneficially affects the host by selectively stimulating the growth and/or activity of one or a limited number of bacteria in the colon, and thus improves host health" [47]. However, the weakness with this definition is that almost every food oligosaccharide and polysaccharide (including dietary fibre) can be claimed to have prebiotic activity. Later, it was proposed that to be allowed to classify a compound as a prebiotic it should scientifically be demonstrated that it resists host digestion, absorption and adsorption processes, is fermented by the microbiota colonising the GI system and selectively stimulates the growth and/or the activity of one or a limited number of bacteria within the GI system [48].
Dietary fiber (DF) is a feed component that has major influence in this regard. Dietary fibre components are not digested by endogenous digestive enzymes, and consequently are the main substrates for bacterial fermentation in the distal part of the gut. The main products of fermentation are short chain organic acids (OA), predominantly lactate, acetate, propionate and butyrate. The OA have been suggested to develop the growth of the digestive tract, by stimulating epithelium cell proliferation [43]. In an acidic environment, OA can inhibit the growth of enteric bacterial pathogens, such as Salmonella, E. coli and Clostridium species [49-51]. Studies in pigs have shown that the various types of plant carbohydrates behave differently in the GIT depending on their structural characteristics. Inclusion of soluble NSP in the diet can stimulate the growth of commensal gut microbes, leading to increased production of $\mathrm{OA}$, and a lower $\mathrm{pH}$ in the large intestine [2]. Insoluble NSP reduce the transit time and provide substrate that is slowly degradable by the microbiota in the distal large intestine [38], and modulate gut morphology by increasing villus length [52].

Feeding guar gum, a soluble and viscous NSP, increases the proliferation of enterotoxigenic E. coli [53], whereas feeding insoluble NSP reduces the occurrence of haemolytic E. coli, and reduces the severity of post weaning colibacillosis [54]. However, it was shown that soluble NSP per se is not detrimental to piglet health [55]. Instead it was stated that soluble NSP that does not increase the digesta viscosity may beneficially affect gut

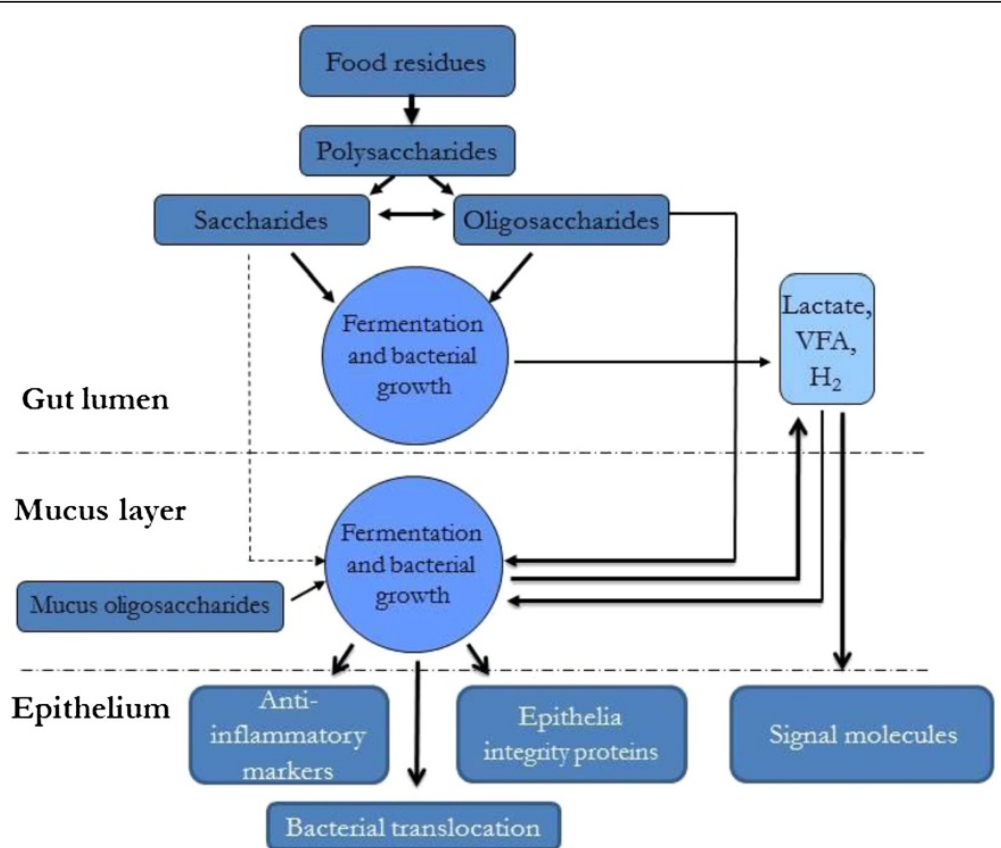

Figure 3 Interactions between dietary fiber, gut environment, gut microbiota and host response with implications on gut health. 
health by increasing the lactobacilli:coliform ratio and decrease the occurrence of weaning diarrhoea.

The impact of DF source on gut microbiota composition and gut micro-environment was nicely demonstrated in a recent study on chicory. The inclusion of chicory (Cichorium intybus L.) forage and root in a cereal-based diet (wheat and barley) results in changes in gut micro-environment and gut morphology of pigs [56], while growth performance was unaffected and digestibility was only marginally reduced by chicory inclusion $[29,57]$. Within diet type, these changes followed a similar pattern in the small and large intestine. However, the dietary responses were different with inclusion of chicory root compared with chicory forage. This could be related to the chemical composition of the dietary fiber fraction [57], where the root is characterized by high content of inulin-type fructan and oligofructose, while the forage is characterized by high content of pectin. The fermentation products and $\mathrm{pH}$ in digesta responded to diet type and were correlated with shifts in the microbiota, showing that chicory influences the intestinal micro-environment of pigs [56]. In ileum, inclusion of chicory roots (inulin-type fructan and oligofructose) was linked with lactic acid concentration in digesta and relative abundance of LAB. In colon, inclusion of chicory forage (pectin) was associated with relative abundance of butyrate-producing bacteria and colonic acetate concentration.

Interestingly, diet fiber intake will have an impact on the expression of intestinal epithelial heat-shock proteins (HSP) that have an important physiological role in the gut. The HSP carry out crucial housekeeping functions in order to maintain the mucosal barrier integrity. In a recent study [58] we found a positive correlation between ileal HSP27 expression and daily total uronic acid intake $(r=0.364, P=0.05)$. This was reinforced when ileal HSP27 and daily soluble uronic acid intake was correlated $(r=0.390, P=0.048)$. Furthermore, HSP27 expression in the ileal mucosa was correlated with mucosa-associated Megasphaera elsdenii (TRF275) $(\mathrm{r}=$ $0.553, P=0.021$ ), which was also positively correlated with daily total uronic acid intake $(\mathrm{r}=0.523, P=0.011)$. However, daily fructan intake was not correlated with HSP27 expression $(P>0.05)$.

\section{Conclusions}

The impact of dietary fiber on pig nutrition and health is determined by the fiber properties and may differ considerably between fiber sources. Moreover, the utilization of plant fiber can be improved by using various techniques and may be improved by breeding for enhanced fiber utilization. There are increasing evidence showing that fiber can have prebiotic effects in pigs due to interactions with the gut micro-environment and the gut associated immune system. This property can be exploited and used as a means to stimulate gut health and thereby minimize the use of anti-microbial growth promoters. In addition, fiber in the diet will increase the satiety, affect behavior and overall improve animal well-being.

\section{Competing interests}

The author declares that there are no competing interests.

Received: 5 November 2013 Accepted: 24 February 2014

Published: 1 March 2014

\section{References}

1. Leeson S: Future considerations in poultry nutrition. Poult Sci 2012, 91:1281-1285.

2. Bach Knudsen KE, Hedemann MS, Laerke HN: The role of carbohydrates in intestinal health of pigs. Anim Feed Sci Technol 2012, 173:41-53.

3. Wenk $C$ : The role of dietary fibre in the digestive physiology of the pig. Anim Feed Sci Technol 2001, 90:21-33.

4. Noblet J, Le Goff Gl: Effect of dietary fibre on the energy value of feeds for pigs. Anim Feed Sci Technol 2001, 90:35-52.

5. de Leeuw JA, Bolhuis JE, Bosch G, Gerrits WJJ: Effects of dietary fibre on behaviour and satiety in pigs. Proc Nutr Soc 2008, 67:334-342.

6. de Lange CFM, Pluske J, Gong J, Nyachoti CM: Strategic use of feed ingredients and feed additives to stimulate gut health and development in young pigs. Livest Sci 2010, 134:124-134.

7. NRC: Nutrient Requirements of Swine. In National Research Council. 11th edition. Washington, USA: National Academy Press; 2012.

8. Bates J, Jordens Z, Selkon J: Evidence for an animal origin of vancomycinresistant enterococci. Lancet 1993, 342(8869):490-491.

9. Levy SB: Microbial resistance to antibiotics. An evolving and persistent problem. Lancet 1982, 2(8289):83-88.

10. Trowell H: Ischemic-heart disease and dietary fiber. Am J Clin Nutr 1972, 25:926.

11. Theander O, Åman P, Westerlund E, Graham H: Enzymatic/chemical analysis of dietary fiber. J AOAC Int 1994, 77:703-709.

12. Bach Knudsen KE: Carbohydrate and lignin contents of plant materials used in animal feeding. Anim Feed Sci Technol 1997, 67:319-338.

13. Champ M, Langkilde AM, Brouns F, Kettlitz B, Collet YL: Advances in dietary fibre characterisation. 1. Definition of dietary fibre, physiological relevance, health benefits and analytical aspects. Nutr Res Rev 2003, 16:71-82.

14. Serena A, Bach Knudsen KE: Chemical and physicochemical characterisation of co-products from vegetable food and agro industries. Anim Feed Sci Technol 2007, 139:109-124.

15. Ngoc TTB, Len NT, Lindberg JE: Chemical characterization and water holding capacity of fibre-rich feedstuffs used for pigs in Vietnam. Asian-Austr J Animal Sci 2012, 25:861-868.

16. Bacic A, Harris PJ, Stone BA: Structure and Function of Plant Cell Walls. In The Biochemistry of Plants: Carbohydrates. San Diego, California, USA: Academic Press Inc; 1988:297-372.

17. McDougall GJ, Morrison IM, Stewart D, Hillman JR: Plant cell walls as dietary fibre: Range, structure, processing and function. I Sci Food Agric 1996, 70:133-150.

18. Bach Knudsen KE: The nutritional significance of "dietary fibre" analysis. Anim Feed Sci Technol 2001, 90:3-20.

19. Kim JC, Mullan BP, Pluske JR: A comparison of waxy versus non-waxy wheats in diets for weaner pigs: effects of particle size, enzyme supplementation, and collection day on total tract apparent digestibility and pig performance. Anim Feed Sci Technol 2005, 120:51-65.

20. Brufau J, Francesh M, Perez-Vendrell AM: The use of enzyme to improve cereal diets for animal feeding. J Sci Food Agric 2006, 86:1705-1713.

21. Mavromichalis I, Hancock JD, Senne BW, Gugle TL, Kennedy GA, Hines RH, Wyatt CL: Enzyme supplementation and particle size of wheat in diets for nursery and finishing pigs. J Anim Sci 2000, 78:3086-3095.

22. Len NT, Ngoc TB, Ogle B, Lindberg JE: lleal and total tract digestibility in local (Mong Cai) and exotic (Landrace $x$ Yorkshire) piglets fed low and high fibre diets, with or without enzyme supplementation. Livest Sci 2009, 126:73-79. 
23. Bedford MR, Classen $\mathrm{HL}$ : Reduction of intestinal viscosity through manipulation of dietary rye and pentosanase concentration is effected through changes in the carbohydrate composition of the intestinal aqueous phase and results in improved growth rate and food conversion efficiency of broiler chicks. J Nutr 1992, 122:560-569.

24. Jensen MS, Bach Knudsen KE, Inborr J, Jakobsen K: Effect of beta-glucanase supplementation on pancreatic enzyme activity and nutrient digestibility in piglets fed diets based on hulled and hulless barley varieties. Anim Feed Sci Technol 1998, 72:329-345.

25. O'Connell JM, Sweeney T, Callan JJ, O'Doherty JV: The effect of cereal type and exogenous enzyme supplementation in pig diets on nutrient digestibility, intestinal microflora, volatile fatty acid concentration and manure ammonia emissions from finisher pigs. Anim Sci 2005, 81:357-364.

26. Ngoc TTB, Len NT, Ogle B, Lindberg JE: Influence of particle size and multi-enzyme supplementation of fibrous diets on total tract digestibility and performance of weaning and growing pigs. Anim Feed Sci Technol 2011, 169:86-95

27. Shi XS, Noblet J: Digestible and metabolizable energy values of 10 feed ingredients in growing pigs fed ad-libitum and sows fed at maintenance level - comparative contribution of the hindgut. Anim Feed Sci Technol 1993, 42:223-236.

28. Jørgensen $H$, Serena A, Hedemann MS, Bach Knudsen KE: The fermentative capacity of growing pigs and adult sows fed diets with contrasting type and level of dietary fibre. Livest Sci 2007, 109:111-114.

29. Ivarsson E, Frankow-Lindberg BE, Andersson K, Lindberg JE: Growth performance, digestibility and faecal coliform bacteria in weaned piglets fed a cereal-based diet including either chicory (Cichorium intybus L) or ribwort (Plantago lanceolata L) forage. Animal 2011, 5(4):558-564.

30. Schinckel AP, Mahan DC, Wiseman TG, Einstein ME: Growth of protein, moisture, lipid, and ash of two genetic lines of barrows and gilts from twenty to one hundred twenty-five kilograms of body weight. J Anim Sci 2008, 86:460-471.

31. Shan T, Wu T, Reng $Y$, Wang $Y$ : Breed differences and regulation of the porcine adipose triglyceride lipase and hormone sensitive lipase by TNFa. Anim Genet 2009, 40:863-870.

32. Guixin Q, Verstegen MWA, Bosch MW: Variation of digestive capacity between genetically different pig populations: a review. J Anim Physiol Anim Nutr 1995, 73:233-242.

33. Schinckel AP, de Lange CFM: Characterization of growth parameters needed as inputs for pig growth models. J Anim Sci 2021-2036, 1996:74.

34. Borin $K$, Lindberg JE, Ogle B: Effect of variety and preservation method of cassava leaves on diet digestibility by indigenous and improved pigs. Anim Sci 2005, 80:319-324.

35. Len NT, Lindberg JE, Ogle B: Digestibility and nitrogen retention of diets containing different levels of fibre in local (Mong Cai), F1 (Mong Cai $x$ Yorkshire) and exotic (Landrace $\mathrm{x}$ Yorkshire) growing pigs in Vietnam. J Anim Physiol Anim Nutr 2007, 91:297-303.

36. Len NT, Hong TTT, Lindberg JE, Ogle B: Comparison of total tract digestibility, development of visceral organs and digestive tract of Mong Cai and Yorkshire $\mathrm{x}$ Landrace piglets fed diets with different fibre sources. J Anim Physiol Anim Nutr 2009, 93:181-191.

37. Ngoc TTB, Len NT, Lindberg JE: Impact of fibre intake and fibre source on digestibility, gastro-intestinal tract development, mean retention time and growth performance in indigenous (Mong Cai) and exotic (Landrace x Yorkshire) pigs. Animal 2013, 7(5):736-745.

38. Freire JPB, Guerreiroa AJG, Cunha LF, Aumaitre A: Effect of dietary fibre source on total tract digestibility, caecum volatile fatty acids and digestive transit time in the weaned piglet. Anim Feed Sci Technol 2000, 87:71-83.

39. Morales J, Perez JF, Martin-Orue SM, Fondevila M, Gasa J: Large bowel fermentation of maize or sorghum-acorn diets fed as a different source of carbohydrates to Landrace and Iberian pigs. Br J Nutr 2002, 88:489-498

40. Freire JPB, Peiniau J, Cunha LF, Almeida JAA, Aumaitre A: Comparative effects of dietary fat and fibre in Alentejano and Landrace piglets: digestibility, digestive enzymes and metabolic data. Livest Prod Sci 1998, 53:37-47.

41. Ngoc TTB, Hong TTT, Len NT, Lindberg JE: Effect of fibre level and fibre source on gut morphology and micro-environment in local (Mong Cai) and exotic (Landrace x Yorkshire) pigs. Asian-Austr J Animal Sci 2012, 25(12):1726-1733.
42. Freire JPB, Dias RIM, Cunha LF, Aumaitre A: The effect of genotype and dietary fibre level on the caecal bacterial enzyme activity of young piglets: digestive consequences. Anim Feed Sci Technol 2003, 106:119-130.

43. Montagne L, Pluske JR, Hampson DJ: A review of interactions between dietary fibre and the intestinal mucosa, and their consequences on digestive health in young non-ruminant animals. Anim Feed Sci Technol 2003, 108:95-117.

44. Bikker P, Dirkzwager A, Fledderus J, Trevisi P, le Huerou-Luron I, Lalles JP, Awati A: The effect of dietary protein and fermentable carbohydrates levels on growth performance and intestinal characteristics in newly weaned piglets. J Anim Sci 2006, 84:3337-3345.

45. Zoetendal EG, Collier CT, Koike S, Mackie Rl, Gaskins HR: Molecular ecological analysis of the gastrointestinal microbiota: a review. $J$ Nutr 2004, 134:465-472.

46. Vaughan EE, Schut F, Heilig HGHJ, Zoetendal EG, de Vos WM, Akkermans ADL: A molecular view of the intestinal ecosystem. Curr Issues Intest Microbiol 2000, 1:1-12.

47. Gibson GR, Roberfroid MB: Dietary modulation of the human colonic microbiota: introducing the concept of prebiotics. J Nutr 1995, 125:1401-1412.

48. Gibson GR, Probert HM, van Loo J, Rastall RA, Roberfroid MB: Dietary modulation of the human colonic microbiota: updating the concept of prebiotics. Nutr Res Rev 2004, 17:259-275.

49. Hentges DJ: Gut Flora and Disease Resistance. In Probiotics: The Scientific Basis. Edited by Fuller R. London: Chapman and Hall; 1992:87-110.

50. Wang $X$, Gibson GR: Effects of the in vitro fermentation of oligofructose and inulin by bacteria growing in the human large intestine. J Appl Microbiol 1993, 75:373-380.

51. May T, Mackie RI, Fahey GC, Cremin JC, Garleb KA: Effect of fibre source on short-chain fatty acid production and on the growth and toxin production by Clostridium difficile. Scand J Gastroenterol 1994, 29:916-922.

52. Hedemann MS, Eskildsen M, Lærke HN, Pedersen C, Lindberg JE, Laurinen $P$, Bach Knudsen KE: Intestinal morphology and enzymatic activity in newly weaned pigs fed contrasting fibre concentrations and fibre properties. J Anim Sci 2006, 84:1375-1386.

53. McDonald DE, Pethick DW, Pluske JR, Hampson DJ: Adverse effects of soluble non-starch polysaccharide (guar gum) on piglet growth and experimental colibacillosis immediately after weaning. Res Vet Sci 1999, 67:245-250

54. Bertschinger HU, Eggenberger E, Jucker H, Pfirter HP: Evaluation of low nutrient, high-fiber diets for the prevention of porcine Escherichia coli Enterotoxaemia. Vet Microbiol 1979, 3:281-290.

55. Wellock IJ, Fortomaris PD, Houdijk JGM, Wiseman J, Kyriazakis I: The consequences of non-starch polysaccharide solubility and inclusion level on the health and performance of weaned pigs challenged with enterotoxigenic Escherichia coli. Br J Nutr 2008, 99:520-530.

56. Liu HY, Ivarsson E, Dicksved J, Lundh T, Lindberg JE: Inclusion of chicory (Cichorium intybus $\mathrm{L}$.) in pigs' diets affects the intestinal microenvironment and the gut microbiota. Appl Environ Microbiol 2012, 78:4102-4109.

57. Ivarsson E, Liu HY, Dicksved J, Roos S, Lindberg JE: Impact of chicory inclusion in a cereal-based diet on digestibility, organ size and faecal microbiota in growing pigs. Animal 2012, 6(7):1077-1085.

58. Liu HY, Lundh T, Dicksved J, Lindberg JE: Expression of heat shock protein 27 in gut tissue of growing pigs fed diets without and with inclusion of chicory fiber. J Anim Sci 2012, 90(Suppl. 4):25-27.

doi:10.1186/2049-1891-5-15

Cite this article as: Lindberg: Fiber effects in nutrition and gut health in pigs. Journal of Animal Science and Biotechnology 2014 5:15. 